\title{
Histomorphological and Histochemical Study of the Uterus of the Adult Guinea Pigs (Cavica porcellus)
}

\author{
F.J. Al-Saffar* and Hazim N.H. Al-Ebbadi
}

Department of Anatomy, College of Veterinary Medicine, University of Baghdad, Baghdad, Iraq; assaffar1955@

yahoo.com, noorhashem559@gmail.com

\begin{abstract}
Objectives: This study was carried out to identify the histomorphological and histochemical aspects of the uterus in the adult guinea pig (Cavica porcellus). To conduct such project, fourteen adult guinea pigs at their diestrous period were bought from the local breeders directly. Methods: Animals were euthanized, dissected, and subsequently uteruses specimens were collected and fixed by $10 \%$ neutral buffered formalin and some specimens were fixed in Bouin's solution for subsequent histochemical staining. Then after specimens were subjected to routine processes such as dehydration, clearing, embedding, and block preparation. Sections of $6 \mu \mathrm{m}$ were prepared and stained with haematoxylin-eosin, Masson's Trichrome, Alcian blue (pH 2.5), and Periodic acid shiff stains. Findings: Gross findings of the uteruses revealed duplex uterus in the guinea pigs. It possessed two separate uterine horns united caudally to form the body, suspended by mesometrium in the abdominal cavity. Caudally, body formed the cervix, which was short and projected into the vaginal cavity forming portio vaginalis uteri with one cervical orifice.Microscopic findings revealed abrupt changes in the wall of the isthmus into the uterine horn at the utero-tubal junction. The wall of the uterus showed endometrium, vascular layer, myometrium, and adventitia or serosa. Lining epithelium was simple columnar which was similarly lined the endometrial glands. Myometrium was consisted of inner circular and outer longitudinal bundles of smooth muscle fibers. In the body, the lining epithelium was replaced gradually by simple mucous columnar epithelium. In addition to that the mucosa was thrown into long folds leaving small lumen at the cervix called os cervix. Such changes were associated with endometrial glands gradual diminishing till the cervix. Histochemically, the non-ciliated columnar cells present in the body and cervix were stained positively with $\mathrm{AB}(\mathrm{pH} 2.5)$ and PAS stains. The reaction with $\mathrm{AB}$ ( $\mathrm{pH}$ 2.5) was more intense compared with the staining with PAS so that it indicated that mucin was more acidic than neutral in nature.
\end{abstract}

Keywords: Guinea Pig, Uterus, Diestrous, Histochemistry.

\section{Introduction}

Domestic guinea pigs (Cavia porcellus) were belonging to their ancestor; the wild cavy (Caviaaperea) which was considered one of the common rodents lived in the South America. This species is herbivorous rodent characterised by their stocky body, short neck and limbs and they were more closely related to porcupines than mice and rats. $1, \underline{2}$
Guinea pigs are widely distributed nowadays because of their popularity as a pet and a food source.

Actually, guinea pigs were frequently used in biomedical research, out of which studies of the human immune system, since their immunological genes are more similar to those of humans than those of mouse, so that considered a very important model for toxicology and vaccine testing. $\underline{3}$

${ }^{*}$ Author for correspondence 
In contrast to the huge number of researches conducted on the reproductive organs of domesticated animal species, few of them and paucity of works were focused on the female reproductive tract of the guinea pigs. In domestic animal, studies were focused on histomorphology of some organs of the female reproductive tract such as oviduct and uterus of does ${ }^{4,5}$; oviducts of the following species, mice, $\underline{6}$ porcupine, $,-\frac{7}{b i t c h}, \underline{8}$ and golden hamster. $\stackrel{9}{\text { Similarly, }}$ few researches were dealt with avian reproductive organs such as in pre- and post-hatched mallard. $10, \underline{11}$

Up to date, four main types of uteri have been identified in different mammalian species based fundamentally on the differences in their body and their related two horns. These were bipartite (in cows), bicornuate (in pigs), simplex of one pear-shaped (in humans and horses), and duplex (in rabbits, guinea pigs, mice, golden hamsters, agouti, and rats). $\underline{5}, \underline{12}-\underline{14}$

Histologically, the uterine wall revealed three histological layers that were endometrium, myometrium, and perimetrium in many species such as agouti, Wistar rats, and albino rat and others. The endometrium enclosed several uterine glands, which were extended into the submucosa region. These glands were lined by simple columnar epithelium. The myometrium was constructed by both circular and longitudinal layers of smooth muscle fibers, intervened between them a vascular layer made up of numerous blood vessels. $., \underline{13}, \underline{15}, \underline{16}$

Currently, there are no available studies in the previous and present literatures investigated the uterus of the adult female guinea pigs. Accordingly, the current project was conducted to study the histomorphology and histochemical aspects of the uterus of the adult female guinea pigs at their diestrous stage of the estrous cycle to provide better understanding basic data to other fields such as pathology, physiology, and pharmacology. The obtained data may be of value in giving basic information on this species for researchers that aim to conduct their researches and the experiments in many medical and veterinary fields.

\section{Materials and Methods}

Fourteen adult female guinea pigs (Cavica porcellus) were selected to conduct the present research. Animals in apparent healthy condition were purchased directly from the local breeders. They were left under supervision to insure their good healthy condition before their euthanasia and subsequent dissection. Each animal weighed with a sensitive weighing balance and euthanized by intramuscular injection of sodium pentobarbitone (140 mg/kg body weight). $\underline{17}$

Then each animal was placed on the dorsal recumbency to view its ventral aspect. Thereafter, a midline abdominal incision was performed cranio-caudal from the xiphoid cartilage to the pubic symphysis which was disarticulated or cut through with bone cutter and pulled apart by lateral traction on either side to expose the organs in the abdominal and pelvic cavities. The uterine horns, body, and cervix were exposed and photographed in situ and later dissected out. The uterus was weighted by sensitive balance, then washed with physiological saline solution and subsequently immersed in fixatives. Macromorphometric measurements included the estimation of relative weight and length of the uterus.

The selected specimens were washed with normal saline and then immersed in 10\% neutral buffered formalin for $48 \mathrm{~h}$. For future staining with histochemical stains, some specimens were fixed by Bouin's solution for $16 \mathrm{~h}$. Next to fixation, specimens were dehydrated through an ascending series of ethyl alcohol (70\%, 80\%, $90 \%$, and $100 \%$ ) each for $2 \mathrm{~h}$, then cleared with xylene for $1 / 2 \mathrm{~h}$. Specimens were infiltrated with paraffin wax (58$60{ }^{\circ} \mathrm{C}$ ) then embedded with new paraffin wax to obtain blocks of paraffin. Paraffin sections of six microns were prepared by using rotary microtome. General histological staining procedure was performed by haematoxylin and eosin (H\&E). Special histochemical procedures were conducted by the following stains: Masson's trichrome stain. Special stain used for the staining of the collagenous connective tissue and the smooth muscle fibers constituting the muscular bundles. Alcian blue $(\mathrm{pH}$ 2.5) technique for the identification of secretory cells of acidic mucopolysaccharides that were observed in the lining endometrium of the uterus. The periodic acid and Schiff reagent (PAS) staining to identify secretory cells of neutral mucopolysaccharides. Histological slides were photographed using the colour USB 2.0 digital image system (Scope Image 9.0) which was provided with image processing software.

\section{Results}

\subsection{Gross Findings}

Gross examination of the present study revealed duplex uterus in the studied guinea pigs, having two separate 
uterine horns united caudally to form the body (Figures $1-3)$. The latter was solid in the texture ended caudally by the cervix. The cervix was projected into the fornix of the vagina as portio-vaginalis uteri with one cervical opening. The uterine horns were longer and having larger diameters than those of corresponding uterine tubes. They were held distinctly by the mesometrium to the dorsal abdominal wall through which passed the supplying blood vessels. It was continuous with mesosalpinx on both right and left sides of the abdominal cavity to form the broad ligament.

Both of uterine horns and the beginning part of the body were situated in the abdominal cavity (Figure 1), whereas most remaining part of the body was located inside the pelvic cavity together with the vagina, pelvic part of the urethra and descending colon (Figure 2). The cranial ends of uterine horns were tapered and were traversed by the thinner uterine tubes.

Caudally, cervix was projected into the vaginal cavity forming portio vaginalis uteri (Figure 3). The intra-pelvic body and the subsequent vagina were running ventrally to the colon and dorsally to the pelvic urethra (Figures 1 and 2).

Morphometrical measurements of the uterine horns and body such as lengths and weights were listed in Table 1. The means of lengths and weights of the uterine horns were $30 \pm 0.50 \mathrm{~mm}$ and $0.61 \pm 0.09 \mathrm{~g}$ so that the relative length and weight were 0.133 and 0.0011 , respectively. The means diameter of uterine horns was $6 \mathrm{~mm}$.

The means of lengths and weights of the body were 12 $\pm 0.44 \mathrm{~mm}$ and $0.96 \pm 0.12 \mathrm{~g}$ so that the relative length and weight were 0.053 and 0.0017 , respectively. The means diameter of uterine horns was $8.2 \mathrm{~mm}$.

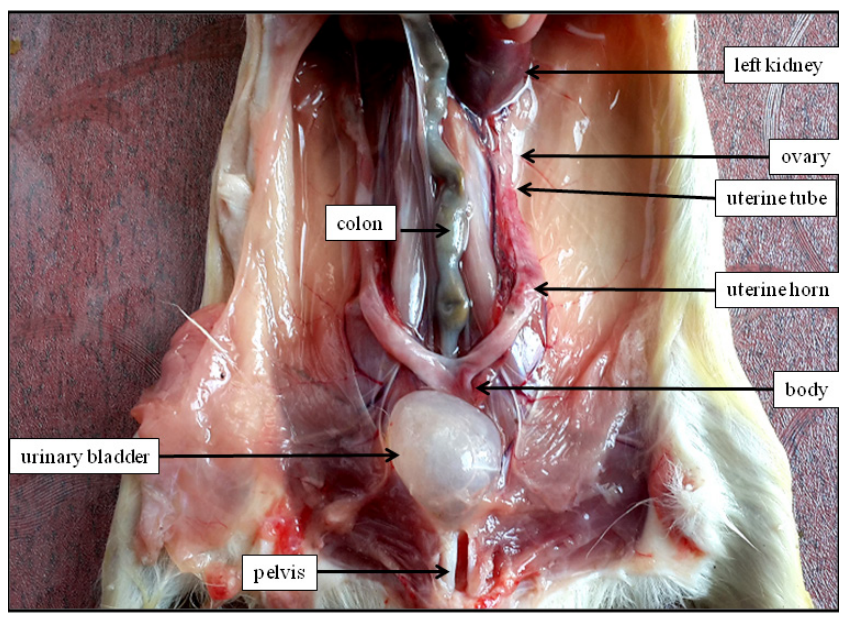

Figure 1. Ovaries and intra-abdominal reproductive tract in situ.

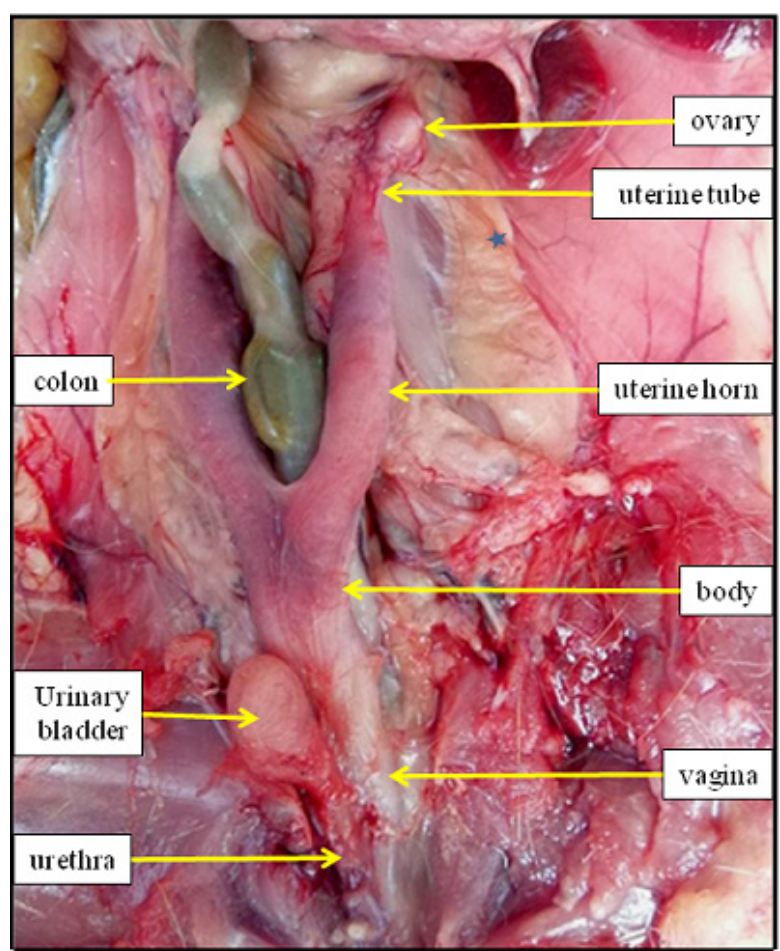

Figure 2. Ovaries, intra-abdominal, and intra-pelvic reproductive tract in situ.

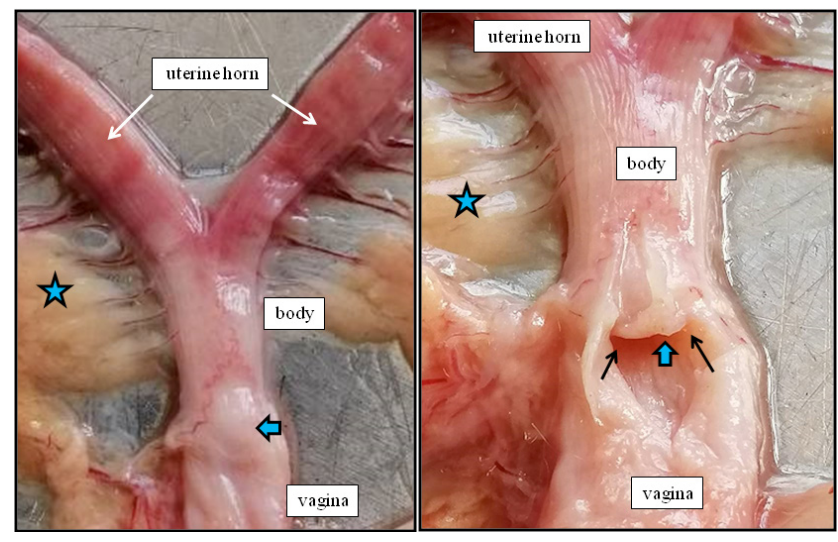

Figure 3. Uterus and beginning of vagina were dissected out, held by broad ligament (blue stars), cervical opening in the intra-vaginalis uteri (blue arrow) surrounded by fornix (black arrows).

\subsection{Microscopic Findings}

The uterus in guinea pigs was duplicated organ constructed of two uterine horns, body, and short cervix. The wall of all regions of the uterus was composed of endometrium myometrium and either serosa (at its free border) or adventitia (at its attached border with the mesometrium). 
Table 1. Macromorphometric measurements of the uterus of adult guinea pigs

\begin{tabular}{|l|l|l|l|l|l|}
\hline organs & $\begin{array}{l}\text { Diameter } \\
(\mathrm{mm})\end{array}$ & $\begin{array}{l}\text { Length } \\
(\mathrm{mm})\end{array}$ & $\begin{array}{l}\text { Relative } \\
\text { length }\end{array}$ & $\begin{array}{l}\text { Weight } \\
(\mathrm{gm})\end{array}$ & $\begin{array}{l}\text { Relative } \\
\text { weight }\end{array}$ \\
\hline $\begin{array}{l}\text { Uterine } \\
\text { horn }\end{array}$ & 6.0 & 30 & 0.133 & 0.61 & 0.0011 \\
\hline body & 8.2 & 12 & 0.053 & 0.96 & 0.0017 \\
\hline $\begin{array}{l}\text { Body weight } \\
(\text { mean } \pm \text { SE })\end{array}$ & $545 \mathrm{gm} \pm 6.03$ & \\
\hline $\begin{array}{l}\text { Body length } \\
\text { (mean } \pm \text { SE })\end{array}$ & $225 \mathrm{~mm} \pm 4.94$ & \\
\hline
\end{tabular}

\subsubsection{Uterine Horns}

Microscopic examination revealed abrupt changes in the wall of the uterine horn compared with uterine tube. In the endometrium, prominently, the lining epithelium looses the mucosal folds that were present in uterine tubes (Figure 4). The diameters of uterine horns were larger than those of the corresponding uterine tubes. The endometrium was lined by simple columnar epithelium which was invaginated into the sub-epithelial connective tissue forming endometrial glands lined with the same epithelium.

The epithelium was rested on wide lamina propria of irregular dense connective tissue with numerous blood vessels (Figure 5). The myometrium showed thicker internal circular muscular layer and thinner

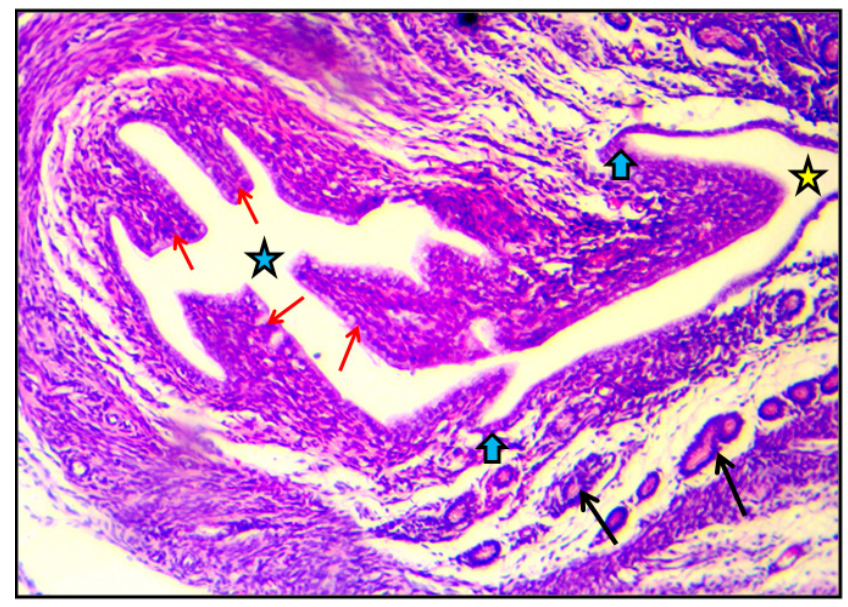

Figure 4. Abrupt junction (blue arrows) between isthmus (blue star) and uterine horn (yellow star). The figure showed mucosal folds of isthmus (red arrows) and endometrial glands in the endometrium (black arrows), X100, H\&E.

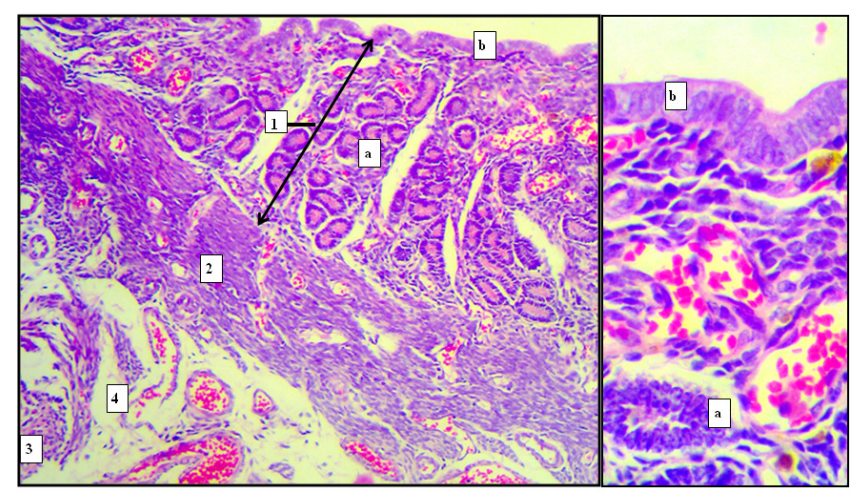

Figure 5. Uterine horn showed endometrium (1) in which present endometrial glands (a) and simple columnar lining epithelium (b), internal circular layer of myometrium (2) and external longitudinal (3) layers of myometrium, vascular layer in between muscular layers (4). X100 (left), X400 (right), H\&E.

external muscular layer of smooth muscle fibers (Figure 6). Characteristically, vascular layer was observed running between internal and external muscular layers of myometrium. This layer was constructed of loose connective tissue with numerous blood vessels (Figures 5 and 6).

\subsubsection{Body}

Examination of serial sections prepared to this organ showed characteristic changes in its wall compared with the uterine horns. In fact, union of right and left uterine

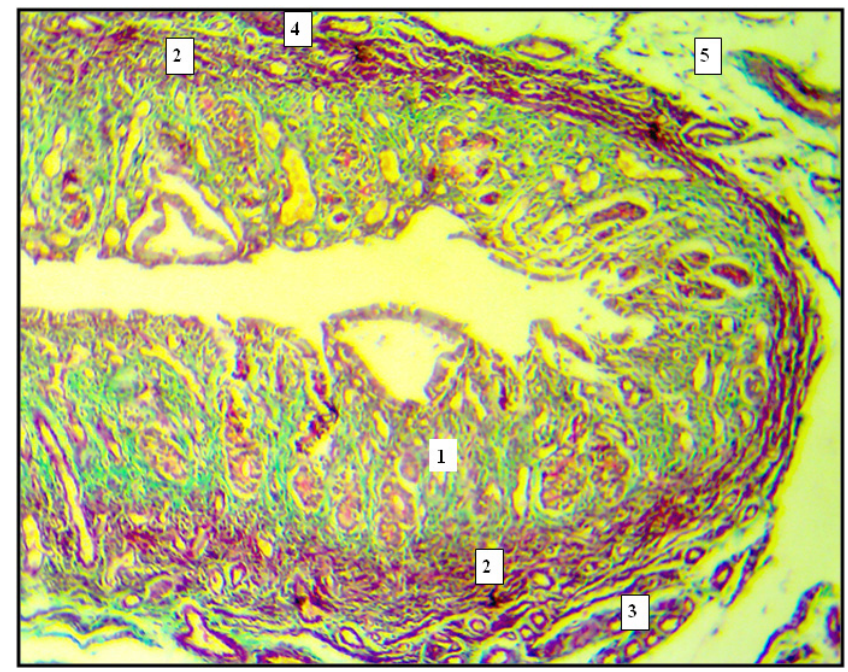

Figure 6. Uterine horn showed endometrial glands (1), internal circular layer of myometrium (2), vascular layer (3) external muscular layer (4) and mesometrium (5). X100, Masson's trichrome stain. 
horns formed the cranial end of the body in the abdominal cavity as mentioned in the gross findings, just before the entrance into the pelvis. At this end, uterine horns were adhered together and both were invested by one external layer of myometrium (Figure 7). Subsequently, inter-septal connective tissue region was diminished and internal layers of myometrium of both horns came close to each other. At the same time, starting the formation of mucosal folds lined with simple mucous columnar epithelium. In addition, endometrial glands were diminished (Figures 7-11).

Histochemical staining with Masson's trichrome showed a wide layer of dense connective tissue lamina propria underneath lining epithelium of the endometrium. The stain showed well distribution of these fibers around endometrial glands. The stain gave green color to the present connective tissue collagenous fibers. The stain gave red-brown color to the smooth muscle fibers of both internal and external layers of myometrium. The stain also showed the connective tissue distributed around the numerous blood vessels of the vascular layer present between layers of myometrium (Figures 6 and 7).

Post staining with $\mathrm{AB}$ ( $\mathrm{pH} 2.5$ ) and PAS, the mucous substances of the columnar cells were stained bluish or pinkish, respectively (Figures 12 and 13). Such reactions indicated the presence of acidic and neutral mucin, respectively. The reaction with $\mathrm{AB}(\mathrm{pH} 2.5)$ was more

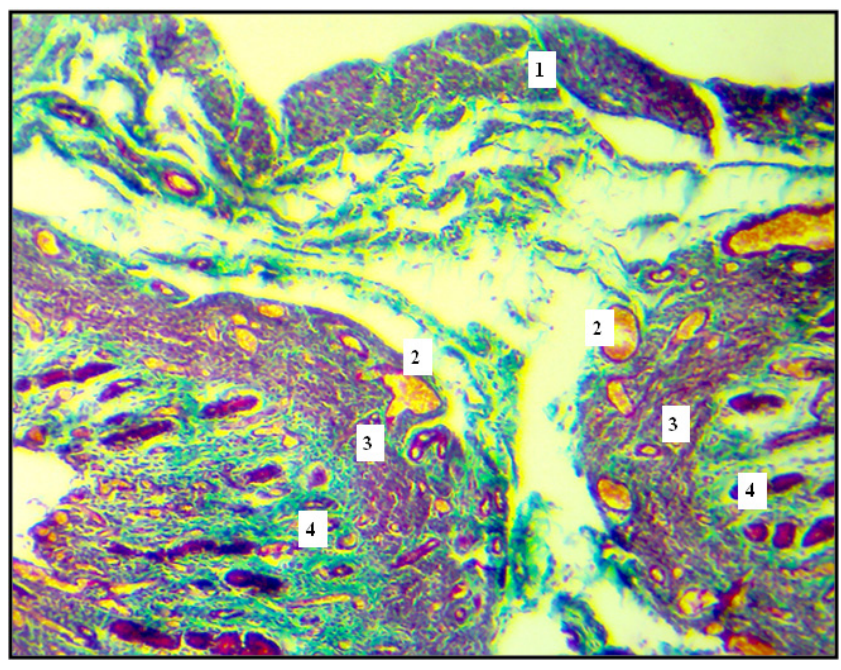

Figure 7. Body of uterus showed uterine horns invested within one longitudinal external layer of myometrium (1), vascular layer (2), circular internal layer of myometrium (3) and endometrial glands (4) in endometrium. X100, Masson's trichrome stain.

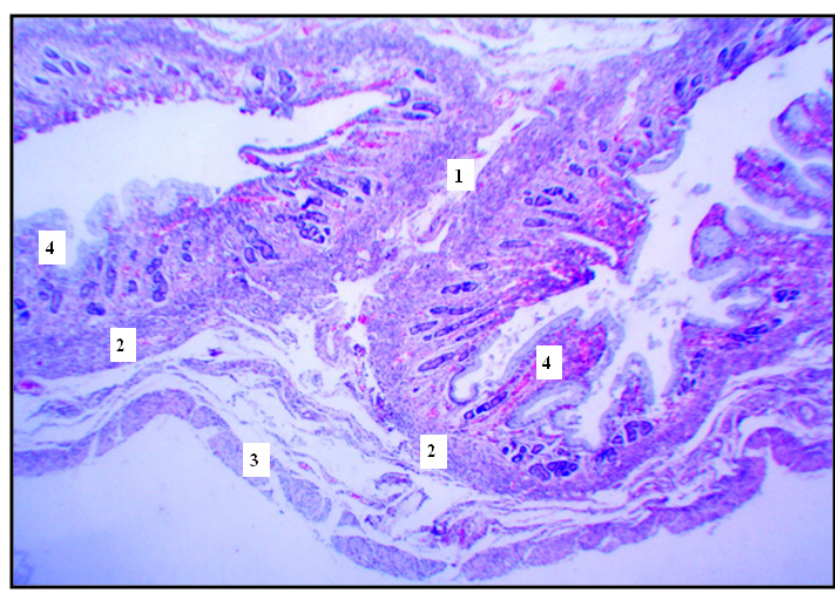

Figure 8. Body of uterus showed adherence of uterine horns (1), circular internal layer of myometrium (2), external layer of myometrium (3), starting of mucosal folds formation covered with mucous simple columnar epithelium (4). X40, H\&E.

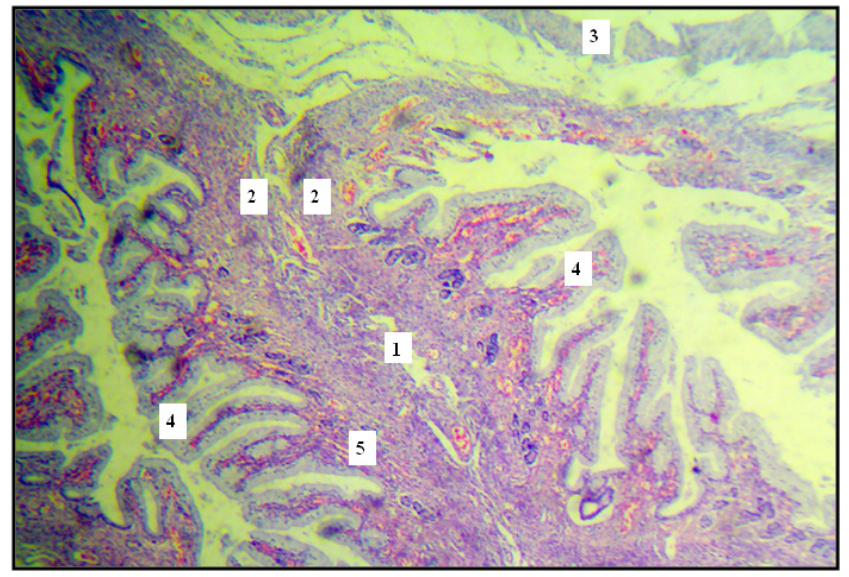

Figure 9. Body of uterus showed union of uterine horns (1), circular internal layer of myometrium (2), external layer of myometrium (3), mucosa formed long mucosal folds covered with mucous simple columnar epithelium (4), diminishing endometrial glands in endometrium (5). X40, H\&E.

incensed compared to the staining with PAS. It indicated that mucin was more acidic than neutral in nature.

Approximately before the middle of the body, the internal myometrium muscular layers adhered and start evanescence process leading to the union of both lumina of the uterine horns (Figure 14) to form one lumen called cervical orifice and the body now forms the cervix. 


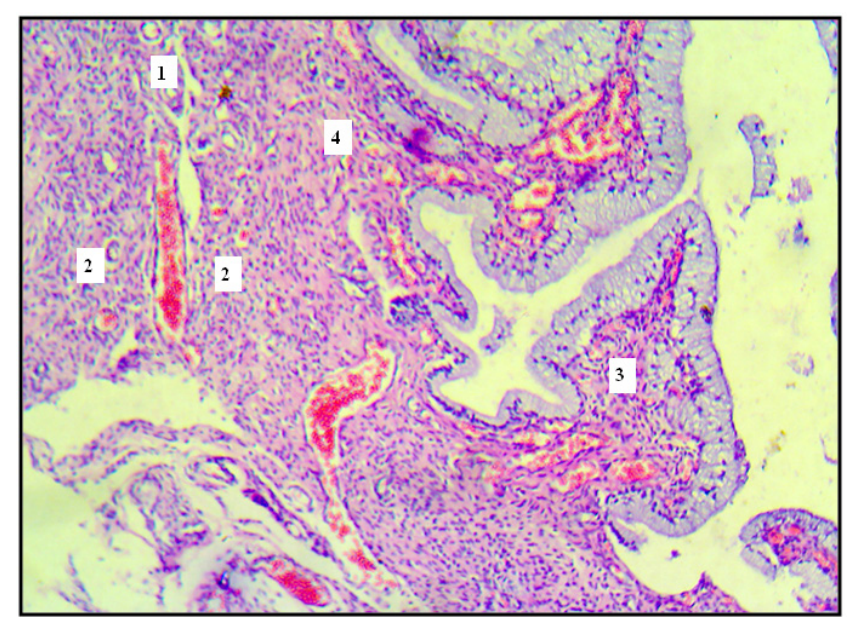

Figure 10. Body of uterus showed union of uterine horns (1), thickening of the circular internal layer of myometrium (2), mucosa formed long mucosal folds covered with mucous simple columnar epithelium (3), diminishing endometrial glands in endometrium (4). X100, H\&E.

\subsubsection{Cervix}

Caudally, the body formed the short cervix. It was characterized by complete mucous simple columnar epithelium, long mucosal folds leaving very small lumen with distinctly thicker internal layer than the thinner external layer of myometrium (Figure 15). Mostly, the mucous of the columnar cells was stained blue after staining with $\mathrm{AB}(\mathrm{pH} 2.5)$ stain only but not with PAS (Figure 16).

\section{Discussion}

Current gross findings indicated that the type of uterus in the guinea pigs was duplex which was similar to other small laboratory species such as does, golden hamsters, agouti, and rats, $\underline{18}$ but was different than others documented types that were bicornuate (in pigs), bipartite (in cows) and finally the simplex type (one pear-shaped found in women and mares).

The body of the uterus in guinea pigs was solid in the texture ended caudally by the cervix which was projected into the fornix of the vagina as portio-vaginalis uteri with one cervical opening. These findings were different from those in does because the two uterine horns ended by two united cervices that were projected into the vagina as two portio vaginalis uteri. Similarly in African giant rat, the uterus was described as uterus duplex in which the two uteri were suspended by the mesometrium which was originated from the dorsolateral pelvic wall and the lumber region. $\underline{19}$ Such remarks were also described in other species such as laboratory rat, $\underline{20}$ the Mongolian gerbil $^{21}$ and female agouti. But in the mouse, the uterus was described differently than in the guinea pigs because it is composed of a cranial part contained two cavities separated by a median septum and undivided caudal portion named the cervix. .22

Similar to the studied guinea pigs, the uterine horns in female agouti were continuing caudally as uterine body. The paired horns were found flattened dorso-ventrally

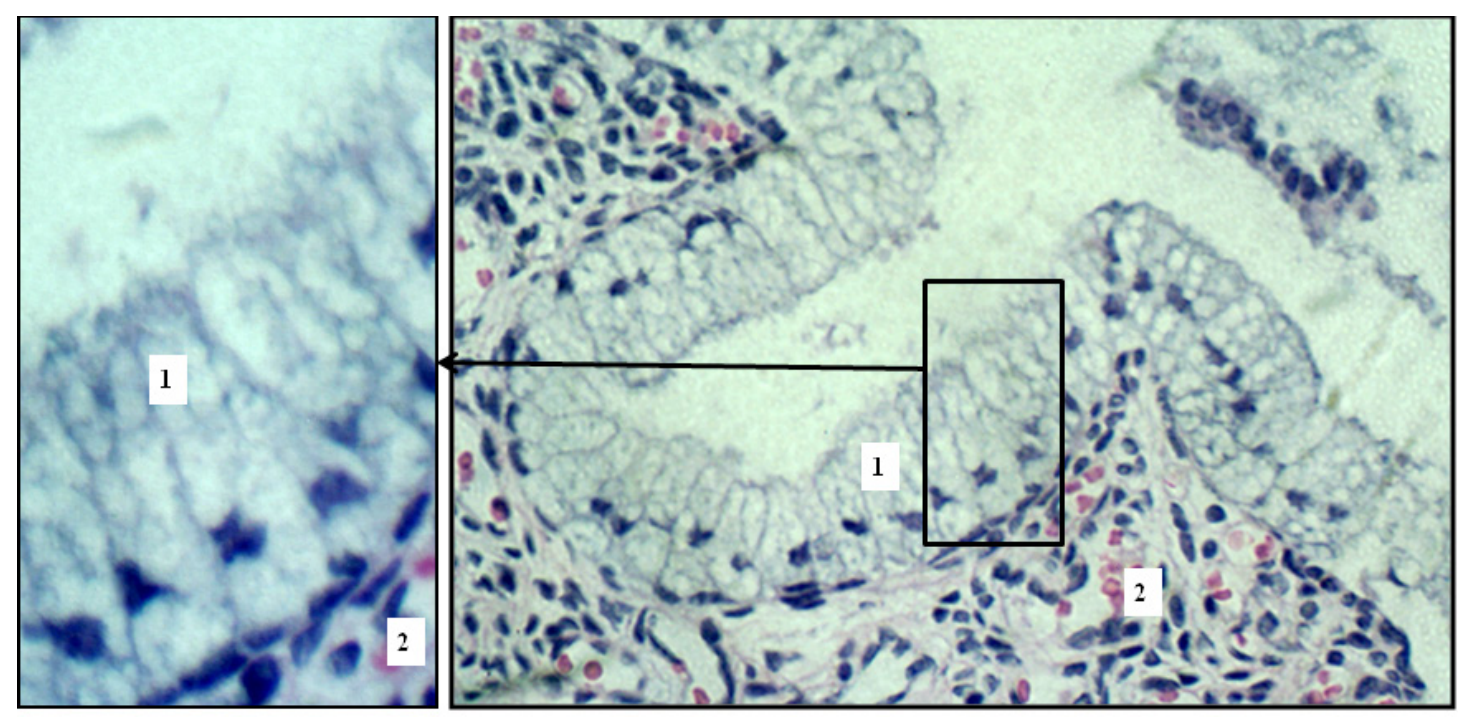

Figure 11. Body of the uterus showed mucosa covered with mucous simple columnar epithelium (1) with underlying connective tissue lamina propria of the endometrium (2). X1000 (left), X400 (right), H\&E. 


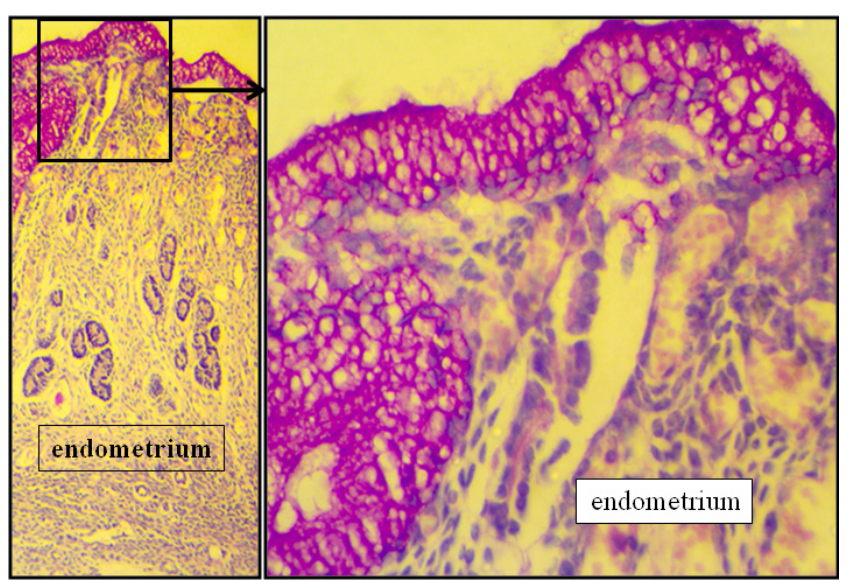

Figure 12. Body of uterus showed mucosa covered with mucous simple columnar epithelium positively reacted to Periodic acid shift stain. X40 (left), X400 (right), PAS.

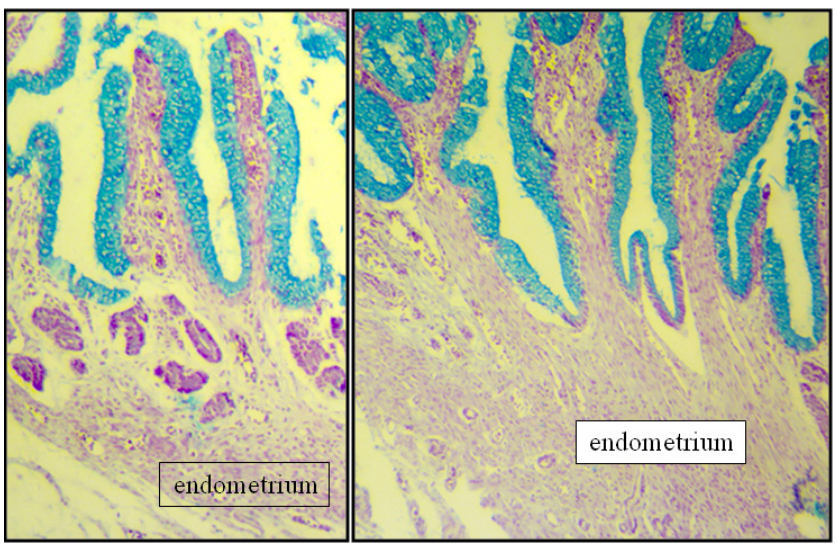

Figure 13. Body of uterus showed mucosa covered with mucous simple columnar epithelium positively reacted to Alcian blue stain. X100 (left \& right), AB.

and were converged together to form the uterine body giving rise to a Y-shape organ.

Similarly to the guinea pigs, recent researches documented two uterine horns in the uteruses of the hamsters and rats leading to the cervix, which in turn leads to the vagina and the vulva but in these species, the cervix composed of upper dual cervix part leading to the two uterine horns and a lower cervix part composed of a single canal that leads to the upper vagina. $\underline{23}$

Current measurements showed that the mean of lengths of the uterine horns in guinea pigs was $30 \pm 0.50$ $\mathrm{mm}$ which appeared longer than in the female agouti $(10.4 \pm 5.5 \mathrm{~mm})$ but in another aspect shorter than those in rats $(3.9 \mathrm{~cm})$, African giant rat $(4.877 \pm 0.011 \mathrm{~cm})$,

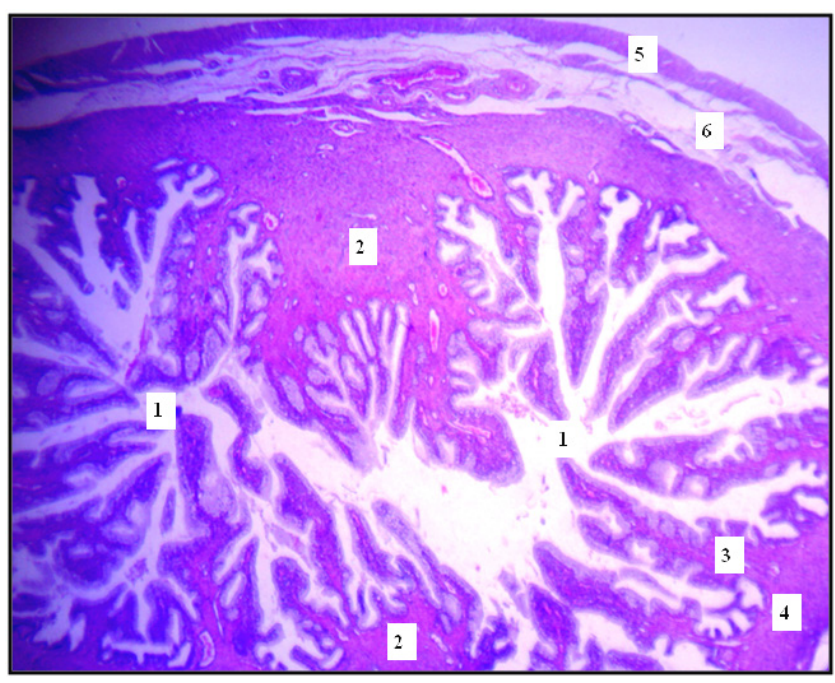

Figure 14. Body of uterus showed union of lumina of uterine horns (1), diminishing of adjacent internal muscular layers (2), increased the lengths of mucosal folds (3), thick internal (4) and thin external (5) muscular layers of myometrium, vascular layer (6). X25, H\&E 2.5, H\&E.

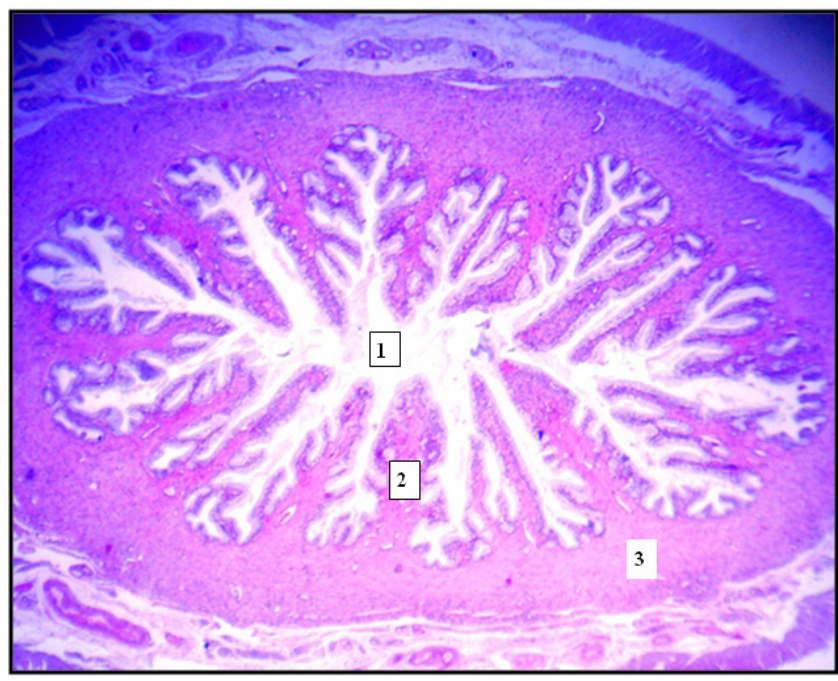

Figure 15. Body at its last part forming the cervix characterized by one small lumen (1), very long cervical mucosal folds (2), thick internal myometrium muscular layer (3). $\mathrm{X} 2.5, \mathrm{H} \& \mathrm{E}$.

local domestic does $(7 \pm 0.01 \mathrm{~cm})$, and in the mixed breed rabbits $(8.07 \pm 0.409 \mathrm{~cm}) . \underline{24}$

Distinctly in the guinea pigs, the wall of the uterotubal junction was abruptly changed from the isthmus to the cranial end of the uterine horn and such finding was dissimilar to the same area in local does in which 


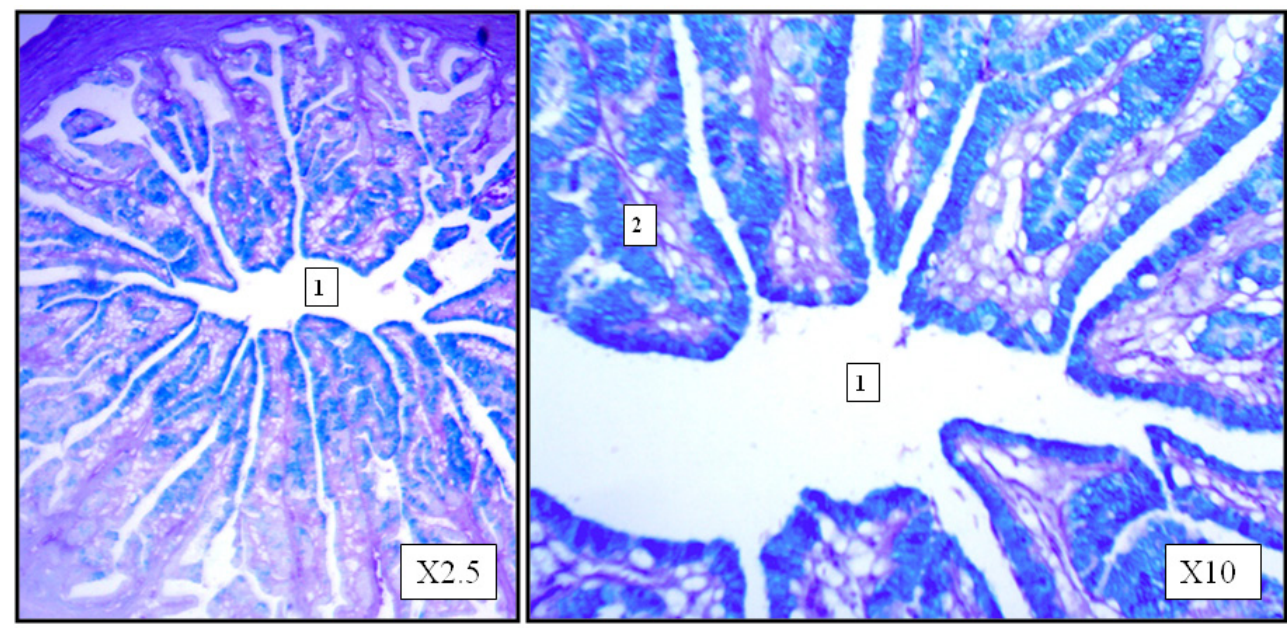

Figure 16. Cervix showed cervical lumen (1), very long cervical mucosal folds (2) covered with simple columnar mucous epithelium stained positively with Alcian blue stain which indicates presence of acidic mucous. X25 (left) and X100 (right), Alcian blue stain.

the junction was gradual and showed very short canal without isthmus folds or uterine crypts that were noted in both joined organs.

Microscopic data showed gradual histological changes between the uterine horns and the body and such findings were non-folded mucosa in the horns became folded in the body ended in the cervix with very long folds leaving a distinct small lumen. Moreover, the lining epithelium changed from non-secretory simple columnar to secretory one as well as diminished uterine glands. These features were unique to the studied guinea pigs and different than other rodents and rabbits which have similarly duplex uteri but have two separate lumina ended by two cervices and cervical openings. In rabbits, body mucosa was lined with simple columnar without secretory cells as in the guinea. Body of uterus in the female agouti also showed histologically two lumina different than in guinea pigs. Similar to the guinea pigs, the uterus of the female African giant rats was also duplex type but differently it possessed partially fused body and two cervices separated by a mid-sagittal septum

Uterus of guinea pig was totally different compared to that found in the mouse. The uterus of the latter possessed cranial part contained two cavities separated by a median septum and undivided caudal portion named the cervix.

The projection of the cervix into the vagina forming portio vaginalis uteri in the uterus of the guinea pigs was also recorded in does, female agouti and female African giant rats.

\section{Conclusions}

Unique feature of the uterus in the guinea pig is duplex as in other species, but its body was ended by one cervical opening instead of two. Histologically, the body of the uterus at diestrous showed mucoid endometrium of acidic and neutral mucin and only acidic at the cervix.

\section{References}

1. Kunzl C, Sachser N. The behavioural endocrinology of domestication: a comparison between the domestic guinea pig (Cavia aperea f. porcellus) and its wild ancestor, the cavy (Cavia aperea). Horm Behav. 1999;35:28-37.

2. North D, Pool T. The UFAW Handbook on the care and management of laboratory animals. Vol. 1. Blackwell Science; 1999. P. 367-88.

3. Guo Y, Bao Y, Meng Q, Hu X, Meng Q, Ren L, Li N, Zhao Y. Immunoglobulin genomics in the guinea pig (Cavia porcellus). PLoS One. 2012;7(6):1-18.

4. Al-Saffar FJ, Almayahi MS. Structural study of uterine tubes of the rabbit (Oryctolagus cuniculus) at different postnatal periods. Iraqi J Vet Sci. 2019;33(2):277-88.

5. Al-Saffar FJ, Almayahi MS. Histomorphological postnatal developmental study of the uteruses of the local rabbits (Oryctologus cuniculus). Indian J Nat Sci. 2018;9(50):14750-61.

6. Stewart CA, Behriner RR. Mouse oviduct development. Results Probl Cell Differ. 2012;55:247-62. 
7. Ozdemir D, Aydin A, Yilmaz S, Dinc G, Atalar O. Observations on the morphology of the ovaries of the porcupine (Hystrix cristata). Vet Arch. 2005;75(2):129-35.

8. Steinhauer N, Boos A, Günzel-Apel AR. Morphological changes and proliferative activity in the oviductal epithelium during hormonally defined stages of the oestrous cycle in the bitch. Reprod Domest Anim. 2004;39(2):110-19.

9. Abe H, Oikawa T. Differentiation of the golden hamster oviduct epithelial cells during postnatal development: an electron microscopic study. J Exp Zool. 1989;252:43-52.

10. Al-Saffar FJ, Abood DA. Histomorphological study of the pre hatching development of the female genital system in indigenous Mallard Duck (Anas platyrhynchos). Int J Adv Res. 2014;2(10):248-63.

11. Abood DA Al-Saffar FJ. The post hatching development of the female genital system in indigenous Mallard Duck (Anas platyrhynchos). Iraqi J Vet Med. 2015;39(2):17-25.

12. Chanut FJA, Williams AM. The Syrian golden hamster estrous cycle: unique characteristics, visual guide to staging, and comparison with the rat. Toxicol Pathol. 2016;44(1):43-50.

13. Singh MD, Adogwa AO, Mollineau WM, Garcia GW. Gross and microscopic anatomy of the reproductive tract of the female agouti (Dasyprocta leporina): a neotropical rodent with potential for food production. Trop Agric (Trinidad). 2014;91(1):38-46.

14. Reproduction and breeding techniques for laboratory animals. [cited 1970 Nov 16]. https://www.amazon.com/ Reproduction-Breeding-Techniques-Laboratory-Animals/ dp/070200362X.

15. Lalithamma A, Naik AG, Changamma C. Cytoarchitectural variations in selected rat tissues following the administration of estradiol valerate in aged female rats. Asian Pac J Reprod. 2016;5(1):36-41.

16. Akpantah AO, Ekong MB, Uruakpa KC, Akpaso MK, Eluwa MA, EkanemTB. Gonadal histo-morphologies and serum hormonal milieu in female rats treated with Azadirachta indica leaf extract. Iran J Reprod Med. 2010;8(4):185-90.

17. Eifler AC, Lewandowski RJ, Virmani S, Chung JC, Wang $\mathrm{D}$, Tang RL, et al. Development of the VX2 pancreatic cancer model in rabbits: a platform to test future interventional radiology therapies. J Vasc Interv Radiol. 2009;20(8):1075-82.

18. Ali MN, Onyeanusi BI, Ojo SA, Ayo JO, Maidawa SM, Imam J. Biometric and morphologic studies of the female reproductive organs of the African giant rat (Cricetomys gambianus: Waterhouse). Folia Morphol. 2010;69(4):213-5.

19. Akinloye AK, Oke AB. Characterization of the uterus and mammary glands of the female African Giant Rats (Cricetomys gambianus, Waterhouse) in Nigeria. International Journal of Morphology. 2010, 28 (1), pp. 93-96.

20. Anatomy of laboratory rats. [cited 1976 Jan 01]. https://www. amazon.com/Anatomy-Laboratory-Rudolf-hebel-Stromberg/ $\mathrm{dp} / 3282023014$.

21. CamilaCD, Patricia FFP, Tania MS, Carls MM, Francisco EM. Estrous cycle anatomy and histology of the uterine tube of the Mongolian gerbil (Meriones unguiculatus). Rev Chil Anat. 2001;19:191-6.

22. Atlasoflaboratorymousehistology.[cited2004].https://www. worldcat.org/title/atlas-of-laboratory-mouse-histology/ oclc/708294658.

23. Hamid HY and Zakaria MZAB. Reproductive characteristics of the female laboratory rat. Afr J Biotechnol. 2013;12(19):2510-14.

24. Bitto II, Arubi JA, Gumel AA. Reproductive tract morphometry and some haematological characteristics of female rabbits fed pawpaw peel meal based diets. Afr J Biomed Res. 2006;9:199-204. 